\title{
Preferential performance of Thal fundoplication for gastroesophageal reflux disease: a single institution experience
}

\author{
Daisuke Ishii ${ }^{1} \cdot$ Kazutoshi Miyamoto ${ }^{1} \cdot$ Masatoshi Hirasawa $^{1} \cdot$ Hisayuki Miyagi ${ }^{1}$
}

Accepted: 6 November 2020 / Published online: 3 January 2021

(c) The Author(s) 2021

\begin{abstract}
Purpose Nissen fundoplication (NF) is the most commonly used surgical treatment for persistent gastroesophageal reflux disease (GERD). We introduced to the alternative Thal fundoplication (TF) (partial anterior wrapping) in 1998. The purpose of this paper is to review and report on the effectiveness of TF in our department.

Methods We retrospectively analyzed cases of 281 patients who underwent TF for GERD at our hospital from 1998 to 2019. Results Average age, $16.3 \pm 18.1$ years; average body weight, $21.0 \pm 16.0 \mathrm{~kg}$; average operative time, $89.1 \pm 43.0$ min; average volume of bleeding, $11.6 \pm 29.2 \mathrm{~g}$; enteral feeding commenced after an average of $3.4 \pm 1.3$ postoperative days (PODs), and average postoperative full enteral feeding was $6.3 \pm 1.4$ PODs. Five patients (1.8\%) had Clavien-Dindo classification III or higher; average hospital stay duration was $10.3 \pm 6.0$ days, with symptom recurrence affecting 17 patients $(6.1 \%)$.

Conclusion TF may be an effective and simple treatment for GERD that has few recurrences and avoids complications common to NF, but further studies to compare it with other techniques are needed.
\end{abstract}

Keywords Gastroesophageal reflux disease $\cdot$ GERD $\cdot$ Anti-reflux procedure $\cdot$ Nissen fundoplication $\cdot$ Thal fundoplication

\section{Introduction}

Gastroesophageal reflux (GER) is also found physiologically in healthy people, especially during infancy, with symptoms often improving with age [1]. However, once GER is associated with any additional symptoms or complications, it is defined as Gastroesophageal reflux disease (GERD). These complications range from esophagitis (resulting from refluxed gastric acid disturbing the esophageal mucosa), aspiration pneumonia (due to the influx of reflux into the trachea), asthma attacks to apnea (via the vagus reflex) amongst others. Such symptoms often promote the occurrence of other conditions [2]. Recently, an association between GERD and apparent life-threatening event has been

Daisuke Ishii

d-ishii@asahikawa-med.ac.jp

Masatoshi Hirasawa

hirasawa@asahikawa-med.ac.jp

Hisayuki Miyagi

miyagi@mvj.biglobe.ne.jp

1 Department of Surgery, Asahikawa Medical University, 2-1-1, Midorigaoka-Higashi, Asahikawashi, Hokkaido 078-8510, Japan reported [2]. This association is especially common amongst patients with severe motor and intellectual disabilities [3]. As such, GERD is one of the major contributors to morbidity and mortality in these patients.

In the past, childhood GER was thought to be caused by an immature of lower esophageal sphincter (LES), that the sphincter could not properly respond to surrounding pressure stimuli. However, we now know that it is caused by transient relaxation of the LES lower, or, by a decrease in intra-abdominal pressure [4, 5].

Surgical treatment should be considered for patients with persistent GERD that resists alternative medical treatment, or those who have difficulty withdrawing from medical treatment. The most common fundoplication procedures are the Nissen fundoplication (NF) (full posterior wrapping), the Toupet fundoplication (partial posterior wrapping) and the Thal fundoplication (TF) (partial anterior wrapping). Among these, the NF is the most popular [6, 7]. In the 1970s and 1980s, we performed the NF for GERD. However, since we experienced longer operative times for laparoscopic surgery and had many postoperative complications (such as gas-bloat syndrome), we considered alternative surgical procedures. As a result, we introduced the TF technique to our surgical department in 1998 because we thought that this approach 
was more physiological, brief and less complicated compared to the NF and the Toupet fundoplication. Therefore, we have reviewed our results obtained with this approach. The purpose of this review was to demonstrate the effectiveness of TF and examine its usefulness over NF.

\section{Materials and methods}

\section{Subject selection}

Subjects included 281 patients who underwent TF for GERD at our hospital from 1998 to 2019. Our department has five indicators for the surgical intervention of GERD, including:

(1) Vomiting, pneumonia, apnea and discomfort,

(2) Other disorders have been ruled out by upper gastrointestinal imaging that also suggested GER,

(3) An esophageal $\mathrm{pH}$-monitored regurgitation rate of $4 \%$ or more,

(4) A modest attempt at other, less invasive treatments and

(5) Granting informed consent to participate in the study.

\section{Quantified variables}

Retrospectively considered variables, including operative method (laparotomy, laparoscopic or laparotomy conversion), simultaneous surgeries at the time of TF, age, body weight, height, underlying disease, operative time (exclusive of any time taken to perform simultaneously performed surgeries, such as a gastrostomy), volume of bleeding, time to commencing postoperative enteral feeding, time to achieving postoperative full enteral feeding, length of hospital stay, complications (Clavien-Dindo classification) [8], and recurrence, were obtained from medical records.

\subsection{Thal fundoplication procedure}

The procedure of TF was outlined in Fig. 1. The abdominal esophagus (at least $3 \mathrm{~cm}$ in length) was taped. After exposing the left and right crura of the diaphragm, the esophageal hiatus was ligated on the dorsal side of the esophagus (Crural repair). Next, the fundus of the stomach was sutured to both the left wall of the abdominal esophagus and left crus of the diaphragm as an anchoring suture to prevent wrap migration. The stomach and left wall of the esophagus were sutured to reconstruct the His angle. Furthermore, the greater curvature of the stomach dome was sutured to both the right wall of the abdominal esophagus and the right crus of the diaphragm as an anchoring suture to prevent wrap migration. The stomach and the right wall of the esophagus were sutured, and wrapping it over $180^{\circ}$ anterior [9].

Our inclusion criteria for laparoscopic surgery are listed below:

(1) Body weight of $5 \mathrm{~kg}$ or more

(2) No history of major surgery (minor operations, such as gastrostomy, were not included)

(3) No severe cardiorespiratory complications

(4) No joint contractures or severe scoliosis
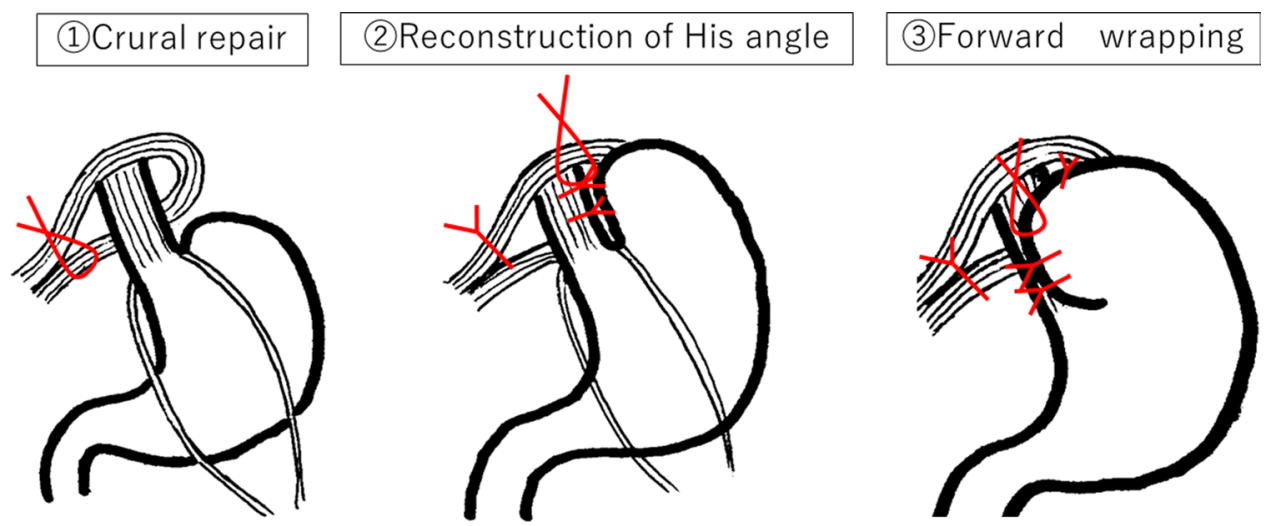

Fig. 1 Thal fundoplication (1) Crural repair After the abdominal esophagus (at least $3 \mathrm{~cm}$ in length) and crura was dissected, the esophageal hiatus was ligated on the dorsal side of the esophagus with non-absorbent thread. This ligation may also be sutured to the posterior esophagus (anchoring suture) to prevent sliding hernia. (2) Reconstruction of His angle The left wall of the abdominal esophagus and the fundus of the stomach were sutured to adequately His angulate, and anchoring suture was added to the left crus of the dia- phragm. The stomach and the left wall of the esophagus were sutured with two more sutures, and reconstruction of the His angle with a total of three sutures. (3) Anterior Wrapping The greater curvature of the stomach dome was sutured to both the right wall of the abdominal esophagus and the right crus of the diaphragm as an anchoring suture to prevent wrap migration. The stomach and the right wall of the esophagus were sutured with two more sutures, and wrapping it over $180^{\circ}$ anterior with a total of three sutures 


\section{Statistical analyses}

Statistical analyses were performed using EZR (Easy R) (Ver. 1.41) [10]. The statistical software EZR, which is based on R and R commander is freely available on the website (http://www.jichi.ac.jp/saitama-sct/SaitamaHP.files /statmed.html) and runs on Windows (Microsoft Corporation, USA). The results were obtained by employing the oneway analysis of variance (ANOVA) and the Steel-Dwass test. When significant differences were detected, post-hoc analyses were performed using Bonferroni's corrections. A $p$ value of $<0.05$ was indicative of statistical significance.

\section{Results}

\section{Patient demographics and outcomes}

Out of all subjects included in this study, there were 263 (93.6\%) patients with severe motor and intellectual disabilities. These included 92 patients with cerebral palsy, 21 patients with hypoxic encephalopathy, 18 patients with encephalitis/encephalopathy and 13 patients with other chromosomal abnormalities. Furthermore, 46 subjects reported an esophageal hiatal hernia.

An average follow-up time was 10 years and 3 months. In our sample population, a patient's average age was $16.3 \pm 18.1$ years with a mean body weight of $21.0 \pm 16.0 \mathrm{~kg}$. Each TF surgery took an average of $89.1 \pm 43.0 \mathrm{~min}$, with an average of $11.6 \pm 29.2 \mathrm{~g}$ of blood loss per patient. Each patient waited an average of $3.4 \pm 1.3$ postoperative days (PODs) before commencing enteral nutrition, with full nutrition achieved at an average of $6.3 \pm 1.4$ PODs. Only five
(1.8\%) patients resulted in a Clavien-Dindo classification of Grade III or higher (i.e., malignant hyperthermia, dysphagia, intestinal obstruction). There were no patients with gas-bloat syndrome among the complications. A patient's average hospital stay was $10.3 \pm 6.0$ days, and $17(6.1 \%)$ patients reported symptom recurrence. The outcomes of all patients are summarized in Table 1.

\section{Technical surgical outcomes}

In our study, laparoscopies were performed on the greatest number of subjects $(197 ; 70.1 \%)$. Laparotomies were performed on $69(24.5 \%)$ subjects, while laparotomy conversions were only performed on 15 (5.3\%) subjects. Laparotomy conversion were due to a poor visual field due to enlargement of the left lobe of the liver and poor pretreatment, giant hiatal hernia, severe adhesions, and bleeding. Average age (years) was laparotomy: laparoscopy: conversion $=9.9 \pm 14.6: 18.1 \pm 18.3: 21.8 \pm 23.43$ (laparotomy vs laparoscopy $p=0.003)$, average body weight $(\mathrm{kg})$ was $15.4 \pm 12.5: 23.0 \pm 16.8: 21.2 \pm 21.2$ (laparotomy vs laparoscopy $p=0.001$ ), average operative time (mins) was 59.1 $\pm 21.9: 99.7 \pm 44.1: 91.7 \pm 75.0$ (laparotomy vs laparoscopy $p<0.001$, laparotomy vs conversion $p=0.01$ ), average volume of bleeding $(\mathrm{g})$ was $20.3 \pm 30.6$ : $7.4 \pm 26.4$ : $26.6 \pm 6.0$ (laparotomy vs laparoscope $p=0.004$, laparoscopic vs conversion $p=0.03$ ), average time to start postoperative enteral nutrition (PODs) was $3.4 \pm 1.6: 3.4 \pm 1.1$ : $3.3 \pm 3.0$ (no significant differences), average time to postoperative full enteral nutrition (PODs) was $6.4 \pm 1.7$ : 6.3 \pm 1.3 : $6.0 \pm 6.0$ (no significant differences), average hospital stay (days) was $10.3 \pm 6.0$ : $10.2 \pm 5.5: 11.9 \pm 8.0$ (no significant

Table 1 Results

\begin{tabular}{llllll}
\hline & & All & Open & Lap & Lap $\rightarrow$ Open \\
\hline$N$ & $n(\%)$ & $281(100)$ & $69(24.56)$ & $197(70.11)$ & $15(5.34)$ \\
Male/Female & & $173 / 108$ & $43 / 26$ & $123 / 74$ & $7 / 8$ \\
Age & years & $16.29 \pm 18.06$ & $9.99 \pm 14.61$ & $18.11 \pm 18.30$ & $21.86 \pm 23.43$ \\
Body weight & $\mathrm{kg}$ & $20.98 \pm 15.98$ & $15.35 \pm 12.49$ & $22.98 \pm 16.82$ & $21.24 \pm 21.20$ \\
Height & $\mathrm{cm}$ & $111.05 \pm 34.47$ & $95.73 \pm 38.19$ & $116.57 \pm 35.36$ & $110.95 \pm 118.20$ \\
Surgery duration & min & $89.11 \pm 43.02$ & $59.14 \pm 21.87$ & $99.68 \pm 44.12$ & $91.67 \pm 75.00$ \\
Volume of bleeding & $\mathrm{g}$ & $11.64 \pm 29.18$ & $20.33 \pm 30.62$ & $7.44 \pm 26.35$ & $26.60 \pm 6.00$ \\
Time to restart feed & PODs & $3.41 \pm 1.26$ & $3.40 \pm 1.64$ & $3.42 \pm 1.13$ & $3.27 \pm 3.00$ \\
Time to full feed & PODs & $6.32 \pm 1.42$ & $6.37 \pm 1.71$ & $6.33 \pm 1.34$ & $6.00 \pm 6.00$ \\
Clavien-Dindo & I & 8 & 3 & 5 & 0 \\
& II & 19 & 5 & 12 & 2 \\
& III & 4 & 0 & 3 & 1 \\
& IV & 0 & 0 & 0 & 0 \\
Length of hospital stay & days & $10.31 \pm 6.00$ & $10.28 \pm 5.96$ & $10.20 \pm 5.54$ & $11.87 \pm 8.00$ \\
Recurrence & $n(\%)$ & $17(6.00)$ & $5(7.24)$ & $12(6.10)$ & $0(0.00)$ \\
\hline
\end{tabular}


differences) and recurrence rate (\%) was 7.2: 5.7: 0.0 (no significant differences).

Some subjects underwent simultaneous surgeries at the time of TF. These included, in order of prevalence, gastrostomy (224 subjects), laryngeal tracheal separation (17 subjects), tracheostomy (14 subjects), diaphragmatic hernia repair (2 subjects), umbilical hernia repair (2 subjects), inguinal hernia repair (2 subjects) and Ladd's operation (2 subjects).

\section{Discussion}

As an intervention for GERD, fundoplication is effectively the surgical reconstruction of the reflux prevention mechanism. It consists of four elements [11]:

(1) Securing of the abdominal esophagus,

(2) Ligation of the esophageal hiatus,

(3) Wrapping of the cardiac part of stomach with the fundus of the stomach and

(4) Fixing of the wrap to the diaphragm crura.

Among these, typical methods of wrapping of the cardiac part of stomach include NF (full posterior wrapping), Toupet fundoplication (partial posterior wrapping), and TF (partial anterior wrapping). NF is the most popular [6,7].

There are few large-scale reports of the TF. Ours is the first report of a single-center study with a large number of cases [12-14]. An anterior partial fundoplication was first described by Thal [15] and later popularized in children by Ashcraft [16].

We report four advantages of preferentially performing TF. First, there is no need to surgically interfere with the short gastric artery and vein. Second, the surgery is brief. Third, herniation of the wrapping valve (wrap migration) does not easily result, and fourth, the prevalence of gas-bloat syndrome is low.

- No need to surgically interfere with the short gastric artery and vein
- Brief surgery and short operative time

In the TF, mobilization of the gastric fundus during fundoplication (partial anterior wrapping) does not require division of short gastric vessels of the spleen and the operation time is short. However, in the NF method, the shoe-shine maneuver or drop test is needed to confirm the free tension of wrap [17]. If the wrap has too much tension, it may be necessary to include a fundus dissection or surgically interfere with the short gastric artery or vein. Under these circumstances, there are risks of splenic bleeds. Three representative papers [18-20] of the Nissen method compared the efficacy and safety of laparoscopies and laparotomies, and we compared our data with respect to TF to this data as well since this report is a single-center, single-operative review (Table 2). On average, our operation time was shorter for both laparoscopic and laparotomy procedures than for the NF. Regarding the length of hospital stay and time to full feed, durations for TF were longer, but we believe that there are due to contributing factors outside the scope of this study as our management method (such as early start of nutrition) that could be improved.

\section{Few wrap migration}

The NF technique is associated with a wrap disruption/ migration rate of 30-40\% [21, 22]. In the reconstruction of the angle of His and the anterior wrapping of our TF technique, we always included anchoring sutures with the left and right crura. This is the reason that the wrap migration does not easily result.

\section{Low prevalence of gas-bloat syndrome}

After NF, dysphagia and gas-bloat syndrome due to gastric hyperinflation tended to be more common [11, 12, 23]; however, the partial wrapping of TF resolved these problems. Only two patients needed dilation for postoperative dysphagia. Supporters of a partial wrap believe in its success, claiming that it fixes the problem of GER while leaving the patient with the ability to vomit and burp
Table 2 Comparison with Nissen Fundoplication

\begin{tabular}{|c|c|c|c|c|c|c|}
\hline \multirow{3}{*}{$\begin{array}{l}\text { References } \\
\text { Open versus Lap }\end{array}$} & \multicolumn{6}{|c|}{ Nissen fundoplication } \\
\hline & \multicolumn{2}{|c|}{ Knatten et al. [18] } & \multicolumn{2}{|c|}{ McHoney et al. [19] } & \multicolumn{2}{|c|}{ Papandria et al. [20] } \\
\hline & Open & Lap & Open & Lap & Open & Lap \\
\hline $\mathrm{N}$ & 44 & 44 & 20 & 19 & 21 & 18 \\
\hline Surgery duration (min) & $89 \pm 25$ & $150 \pm 34$ & $80 \pm 5$ & $160 \pm 15$ & $89.25 \pm 6.25$ & $167 \pm 10.5$ \\
\hline Length of hospital stay (days) & 7.5 & 7 & 4.5 & 5 & 4.75 & 4.75 \\
\hline Time to full feed (PODs) & - & - & 2 & 2 & - & - \\
\hline Recurrence $(\%)$ & 7 & 37 & 12 & 20 & 4.8 & 5.6 \\
\hline
\end{tabular}


should the need arise. In addition, NF indicates that the wrap should be short and loose [24, 25]. Loose and short wraps are largely left to the discretion of the surgeon, since there is no clear standard. We believe that partial wraps are more reliable and safer; however, the risks associated with surgical treatment and recurrence of GERD cannot be overlooked. In our data, GERD recurrence rate was $6 \%$. Many reports have shown that there is no significant difference in recurrence rates between the NF, the Toupet fundoplication, and the TF [26-30]. Further, there is no significant difference in recurrence rates between anterior and posterior wrapping or full and partial wrapping. We believe that the recurrence rate was also comparable (Table 2).

In recent years, there have been many reports comparing laparoscopic and laparotomy with the NF [7, 30, 31]. Laparoscopic NF has been shown to be a safe, feasible, and effective surgical procedure alternative to open NF for gastroesophageal reflux in children [7, 30, 31]. We believe that the advantage of laparoscopic TF is similar to the NF. Infants weighing less than $5 \mathrm{~kg}$ are excluded from laparoscopic surgery because of the small working space for laparoscopic surgery. Therefore, our results showed that there was a significant difference in age $(9.9 \pm 14.6$ : $18.1 \pm 18.3$ years $)$ and body weight $(15.4 \pm 12.5$ : $23.0 \pm 16.8$ ) in open surgery compared to laparoscopic surgery for this group. Further, the volume of bleeding during laparoscopic surgery was significantly less than that of open surgery $(20.3 \pm 30.6: 7.4 \pm 26.4 \mathrm{~g})$. Time to start postoperative enteral nutrition $(3.4 \pm 1.6: 3.4 \pm 1.1 \mathrm{PODs})$, time to postoperative full enteral nutrition $(6.4 \pm 1.7$ : $6.3 \pm 1.3$ : PODs $)$ and length of hospital stay $(10.3 \pm 6.0$ : $10.2 \pm 5.5$ days) showed no significant differences between laparoscopic and open surgeries. We were able to complete laparoscopic surgery in 197 (92.9\%) of the 212 cases that underwent laparoscopic surgery. Previous studies have reported that, for NF, laparoscopic surgery should be considered an acceptable option for children [30], and we believe the same is true for TF.

\section{Conclusion}

TF did not have a high recurrence rate and was considered effective for treating GERD, but further studies to compare it with other techniques are needed.

Acknowledgments We would like to thank Editage (www.editage.com) for English language editing. This work was supported by a Grants-inaid of The Ishidsu Shun Memorial Scholarship, Japan.

Funding No funding has been received for this work.

\section{Compliance with ethical standards}

Conflict of interest The authors declare no conflicts of interest associated with this manuscript.

Informed consent The authors hereby confirm that informed consent was obtained from all individual patients included in this study.

Ethical approval All procedures performed involving human participants were in accordance with the ethical standards of the Clinical Research Center, Asahikawa Medical University, Japan and with the 1964 Helsinki Declaration and its later amendments or comparable ethical standards.

Open Access This article is licensed under a Creative Commons Attribution 4.0 International License, which permits use, sharing, adaptation, distribution and reproduction in any medium or format, as long as you give appropriate credit to the original author(s) and the source, provide a link to the Creative Commons licence, and indicate if changes were made. The images or other third party material in this article are included in the article's Creative Commons licence, unless indicated otherwise in a credit line to the material. If material is not included in the article's Creative Commons licence and your intended use is not permitted by statutory regulation or exceeds the permitted use, you will need to obtain permission directly from the copyright holder. To view a copy of this licence, visit http://creativecommons.org/licenses/by/4.0/.

\section{References}

1. Miyazawa R, Tomomasa T, Kaneko H, Tachibana A, Ogawa T, Morikawa A (2002) Prevalence of gastro-esophageal refluxrelated symptoms in Japanese infants. Pediatr Int 44:513-516

2. Okada K, Miyako M, Honma S, Wakabayashi Y, Sugihara S, Osawa M (2003) Discharge diagnoses in infants with apparent life-threatening event. Pediatr Int 45:560-563

3. Ohhama Y, Yamamoto H, Yamada R, Nishi T, Tsunoda A (1991) Nissen fundoplicationfor severelyretarded children suffering from gastroesophageal reflux. J Jpn Soc Pediatr Surg 27:214-218

4. Kawahara H, Dent J, Davidson G (1997) Mechanisms responsible for gastroesophageal reflux in children. Gastroenterology 113:399-408

5. Kawahara H, Dent J, Davidson G, Okada A (2001) Relationship between straining, transient lower esophageal sphincter relaxation, and gastroesophageal reflux in children. Am J Gastroenterol 96:2019-2025

6. Iwanaka T, Kanamori Y, Sugiyama M, Komura M, Tanaka Y, Kodaka T, Ishimaru T (2010) Laparoscopic fundoplication for gastroesophageal reflux disease in infants and children. Surg Today 40:393-397

7. Ru W, Wu P, Feng S, Lai XH, Chen G (2016) Laparoscopic versus open Nissen fundoplication in children: a systematic review and meta-analysis. J Pediatr Surg 51:1731-1736

8. Dindo D, Demartines N, Clavien PA (2004) Classification of surgical complications: a new proposal with evaluation in a cohort of 6336 patients and results of a survey. Ann Surg 240:205-213

9. Mattei P (2003) Surgical directives pediatric surgery. Philadelphia, USA

10. Kanda Y (2013) Investigation of the freely available easy-to-use software "EZR" for medical statistics. Bone Marrow Transplant 48:452-458

11. Sakai K, Furukawa T, Kimura O, Higashi M, Fumino S, Aoi S, Tajiri T (2016) Comparison of outcomes of anterior wrapping 
and posterior wrapping in laparoscopic fundoplication. J Jpn Soc Pediatr Surg 52:78-82

12. Kubiak R, Andrews J, Grant HW (2011) Long-term outcome of laparoscopic Nissen fundoplication compared with laparoscopic thal fundoplication in children: a prospective, randomized study. Ann Surg 253:44-49

13. Hu JM, Hu M, Wu YM, Wang J, Yan ZL, Zhang C, Pan WH, Xia H (2016) Long-term outcome of laparoscopic Nissen-Rossetti fundoplication versus Thal fundoplication in Children with esophageal hiatal hernia: a retrospective report from two children's medical centers in Shanghai. World J Pediatr 12:231-235

14. Kubiak R, Böhm-Sturm E, Svoboda D, Wessel LM (2014) Comparison of long-term outcomes between open and laparoscopic thal fundoplication in children. J Pediatr Surg 49:1069-1074

15. Thal AP (1968) A unified approach to surgical problems of the esophagogastric junction. Ann Surg 168:542-550

16. Ashcraft KW, Goodwin CD, Amoury RW (1978) Thal fundoplication: a simple and safe operative treatment for gastroesophageal reflux. J Pediatr Surg 13:643-647

17. Omura N, Kashiwagi H (2010) Anti-reflux procedure. Kyobu Geka 63:749-753

18. Knatten CK, Fyhn TJ, Edwin B, Schistad O, Emblem R, Bjørnland $\mathrm{K}$ (2012) Thirty-day outcome in children randomized to open and laparoscopic Nissen fundoplication. J Pediatr Surg 47:1990-1996

19. McHoney M, Wade AM, Eaton S, Howard RF, Kiely EM, Drake DP, Curry JI, Pierro A (2011) Clinical outcome of a randomized controlled blinded trial of open versus laparoscopic Nissen fundoplication in infants and children. Ann Surg 254:209-216

20. Papandria D, Goldstein SD, Salazar JH, Cox JT, McIltrot K, Stewart FD, Arnold M, Abdullah F, Colombani P (2015) A randomized trial of laparoscopic versus open Nissen fundoplication in children under two years of age. J Pediatr Surg 50:267-271

21. Hainaux B, Sattari A, El C, Sadeghi N, Cadière GB (2002) Intrathoracic migration of the wrap after laparoscopic Nissen fundoplication: radiologic evaluation. AJR Am J Roentgenol 178:859-862

22. Doi T, Ichikawa S, Miyano G, Lane GJ, Miyahara K, Yamataka A (2008) A new technique for preventing wrap disruption/migration after laparoscopic Nissen fundoplication: an experimental study. J Laparoendosc Adv Surg Tech A 18:179-182
23. Khan M, Smythe A, Globe J, Stoddard CJ, Ackroyd R (2010) Randomized controlled trial of laparoscopic anterior versus posterior fundoplication for gastro-oesophageal reflux disease. ANZ J Surg 80:500-505

24. Feussner H, Wilhelm D (2013) Antireflux operations: indications and techniques. Chirurg 84:339-350

25. Raiser F, Hinder RA, McBride PJ, Katada N, Filipi CJ (1995) The Technique of laparoscopic Nissen fundoplication. Chest Surg Clin N Am 5:437-548

26. Daud WNW, Thompson SK, Jamieson GG, Devitt PG, Martin IJG, Watson DI (2015) Randomized controlled trial of laparoscopic anterior $180^{\circ}$ partial versus posterior $270^{\circ}$ partial fundoplication. Anz J Surg 85:668-672

27. Roks DJ, Koetje JH, Oor JE, Broeders JA, Nieuwenhuijs VB, Hazebroek EJ (2017) Randomized clinical trial of $270^{\circ}$ posterior versus $180^{\circ}$ anterior partial laparoscopic fundoplication for gastro-oesophageal reflux disease. Br J Surg 104:843-851

28. Chew CR, Jamieson GG, Devitt PG, Watson DI (2011) Prospective randomized trial of laparoscopic Nissen fundoplication with anterior versus posterior hiatal repair: late outcomes. World J Surg 35:2038-2044

29. Jancelewicz T, Lopez ME, Downard CD, Islam S, Baird R, Rangel SJ, Williams RF, Arnold MA, Lal D, Renaud E, Grabowski J, Dasgupta R, Austin M, Shelton J, Cameron D, Goldin AB (2017) Surgical management of gastroesophageal reflux disease (GERD) in children: a systematic review. J Pediatr Surg 52:1228-1238

30. Zhang P, Tian J, Jing L, Wang Q, Tian J, Lun L (2016) Laparoscopic vs. open Nissen's fundoplication for gastro-oesophageal reflux disease in children: a meta-analysis. Int J Surg 34:10-16

31. Lei X, Ren Q, Yang Y, Bai T (2017) Outcome evaluation of laparoscopic and open Nissen fundoplication in children-a systematic review and meta-analysis. Am Surg 83:90-97

Publisher's Note Springer Nature remains neutral with regard to jurisdictional claims in published maps and institutional affiliations. 